\title{
Stella Van Praagh (March 18, 1927-June 3, 2006)
}

S tella Van Praagh died on June 3, 2006, following a brief illness. She was a worldrenowned paediatric cardiologist and paediatric cardiac pathologist, whose dedication to education in the field of congenital cardiac disease was legendary.

Born Stella Zacharioudaki in Rethymnon, Crete, Greece, she graduated from the School of Medicine of the University of Athens in 1952. She pursued postgraduate training in paediatric cardiology in the United States of America and Canada, most notably training as a cardiology fellow with Helen Taussig at Johns Hopkins. While a research associate at Buffalo Children's Hospital, she met and, in 1962, married Richard Van Praagh, commencing a true lifetime partnership in work and love. Stella and Richard were invited to join the staff of Children's Hospital Boston in 1965, and until their retirement in 2002, they developed the Cardiac Registry as a centre for advancing the understanding of the pathology of congenital cardiac disease. Stella was the author of more than 100 scientific publications, and possessed clarity of thought and language that made even the most complicated of cardiac malformations comprehensible.

To the hundreds of paediatric cardiologists, pathologists, and cardiac surgeons that visited the Cardiac Registry, nonetheless, Stella is best remembered for her baklava, bread, and the kindness she showed to junior trainees who wanted to learn even a fraction of all she understood of the human heart. She was a master educator, and superb clinical cardiologist, whose primary goal was to do the best that she could for her patients and their families. She took great joy in hearing from her patients at the holidays, news of graduations, marriages and healthy babies. She also shared in their sorrows when her patients were ill, or died. Stella was dedicated to her own family, Richard, their sons Andrew and Alexander, and daughter Helen, who died in 2001. Since her retirement, she had devoted her time to her grandchildren, and to pursuing her enormous intellectual curiosity across many disciplines, including history and languages.

Stella had a wonderful collection of Greek proverbs, which summed up universal truths in a few words.

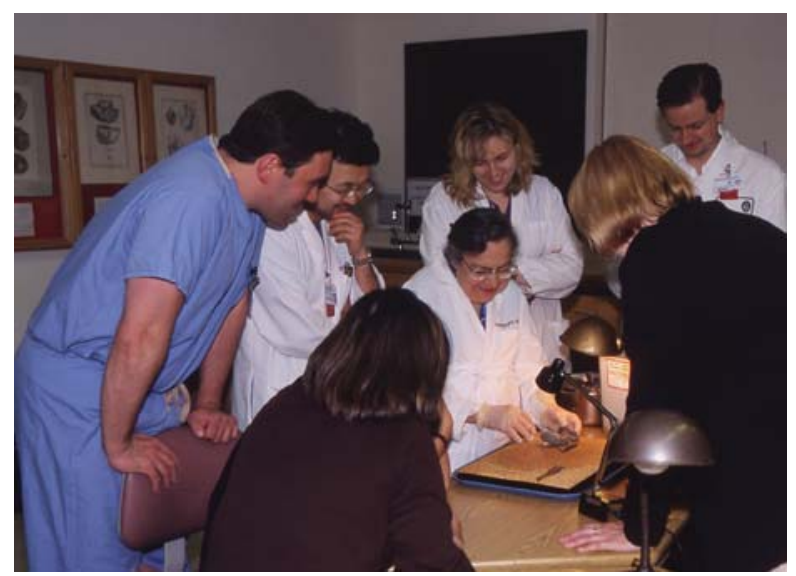

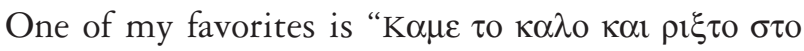
r $\alpha \lambda \mathrm{O}$ " which translates as "take a good thing and throw it in the sea". As with most things in life, there are multiple interpretations: one being that we cannot hold on to things too tightly; another being that we need to share the good things that life brings us. Stella's generosity of spirit has touched countless lives through the cardiologists, pathologists and surgeons she taught, and the patients that Stella's students went on to care for.

At the memorial service for Dick Rowe in 1988, Stella herself said "in times like these, when a very special friend is gone forever, I wish I had the talent of a poet - to intertwine my sorrow with a scene from nature and create a lasting wreath of love, which I could dedicate to the memory of the lost friend." May these words create a wreath for Stella to continue her legacy of compassion, education, and intellectual curiosity.

Amy L. Juraszek Medical Director, Cardiac Registry Children's Hospital Boston 300 Longwood Ave, Boston, MA 02115, USA E-mail:amy.juraszek@cardio.chboston.org 